Prolog Programming and Applications 


\section{Macmillan Computer Science Series}

\section{Consulting Editor}

Professor F. H. Sumner, University of Manchester

\section{S. T. Allworth, Introduction to Real-time Software Design}

Ian O. Angell, A Practical Introduction to Computer Graphics

R. E. Berry and B. A. E. Meekings, $A$ Book on $C$

G. M. Birtwistle, Discrete Event Modelling on Simula

T. B. Boffey, Graph Theory in Operations Research

Richard Bornat, Understanding and Writing Compilers

J. K. Buckle, Software Configuration Management

W. D. Burnham and A. R. Hall, Prolog Programming and Applications

J. C. Cluley, Interfacing to Microprocessors

Robert Cole, Computer Communications

Derek Coleman, $A$ Structured Programming Approach to Data

Andrew J. T. Colin, Fundamentals of Computer Science

Andrew J. T. Colin, Programming and Problem-solving in Algol 68

S. M. Deen, Fundamentals of Data Base Systems

S. M. Deen, Principles and Practice of Database Systems

P. M. Dew and K. R. James, Introduction to Numerical Computation in Pascal

M. R. M. Dunsmuir and G. J. Davies, Programming the UNIX System

K. C. E. Gee, Introduction to Local Area Computer Networks

J. B. Gosling, Design of Arithmetic Units for Digital Computers

Roger Hutty, Fortran for Students

Roger Hutty, Z80 Assembly Language Programming for Students

Roland N. Ibbett, The Architecture of High Performance Computers

Patrick Jaulent, The 68000 - Hardware and Software

J. M. King and J. P. Pardoe, Program Design Using JSP - A Practical Introduction

H. Kopetz, Software Reliability

E. V. Krishnamurthy, Introductory Theory of Computer Science

V. P. Lane, Security of Computer Based Information Systems

Graham Lee, From Hardware to Software - an introduction to computers

A. J. Lister, Fundamentals of Operating Systems, third edition

G. P. McKeown and V. J. Rayward-Smith, Mathematics for Computing

Brian Meek, Fortran, PL/I and the Algols

Barry Morrell and Peter Whittle, $C P / M 80$ Programmer's Guide

Derrick Morris, System Programming Based on the PDP11

Pim Oets, $M S$-DOS and PC-DOS - A Practical Guide

Christian Queinnec, LISP

John Race, Case Studies in Systems Analysis

W. P. Salman, O. Tisserand and B. Toulout, FORTH

L. E. Scales, Introduction to Non-linear Optimization

Peter S. Sell, Expert Systems - A Practical Introduction

Colin J. Theaker and Graham R. Brookes, A Practical Course on Operating

Systems

J. M. Trio, 8086-8088 Architecture and Programming

M. J. Usher, Information Theory for Information Technologists

B. S. Walker, Understanding Microprocessors

Peter J. L. Wallis, Portable Programming

I. R. Wilson and A. M. Addyman, A Practical Introduction to Pascal - with BS6192, second edition 


\title{
Prolog Programming and Applications
}

\author{
W.D. Burnham \\ and \\ A.R. Hall
}




() W. D. Burnham and A. R. Hall 1985

All rights reserved. No reproduction, copy or transmission of this publication may be made without written permission.

No paragraph of this publication may be reproduced, copied or transmitted save with written permission or in accordance with the provisions of the Copyright Act 1956 (as amended).

Any person who does any unauthorised act in relation to this publication may be liable to criminal prosecution and civil claims for damages.

First published 1985

Published by

MACMILLAN EDUCATION LTD

Houndmills, Basingstoke, Hampshire RG21 2XS

and London

Companies and representatives

throughout the world

Typeset by TecSet Ltd, Sutton, Surrey

ISBN 978-0-333-39159-4

ISBN 978-1-349-07962-9 (eBook)

DOI $10.1007 / 978-1-349-07962-9$ 


\section{Contents}

Preface

viii

Acknowledgements

$x i$

1 Introducing the Language

1.1 Writing assertive statements

1.2 Syntax requirements

1.3 More complex statements

1.4 Exercise 1

15 Formulating rules

1.6 Exercise 2

1.7 Building and questioning a knowledge base

1.8 Introducing rules to the knowledge base 11

$\begin{array}{lll}1.9 & \text { Exercise } 3 & 12\end{array}$

$\begin{array}{ll}1.10 \text { Summary of syntax rules } & 12\end{array}$

$\begin{array}{ll}1.11 \text { Solutions to exercises } & 14\end{array}$

$\begin{array}{ll}1.12 \text { Practical projects } & 16\end{array}$

2 The Structure of the Language 17

$\begin{array}{lll}2.1 & \text { Predicates and arguments } & 17\end{array}$

$\begin{array}{ll}2.2 & \text { The idea of goals in Prolog } \\ 2.3\end{array}$

$\begin{array}{ll}2.3 \text { Structures within Prolog clauses } & 19\end{array}$

$\begin{array}{lll}2.4 & \text { Exercise } 4 & 22\end{array}$

2.5 The 'blank' variable $\quad 22$

2.6 Search and pattern matching $\quad 24$

$\begin{array}{lll}2.7 & \text { Exercise 5 } & 28\end{array}$

$\begin{array}{lll}2.8 \text { Diagrammatic representation of } & 28\end{array}$

2.9 Solutions to exercises $\quad 29$

3 Arithmetic, the "Cut" Symbol, and

Recursion

$\begin{array}{lll}3.1 & \text { Arithmetic } & 31\end{array}$

$\begin{array}{lll}3.2 & \text { Exercise } 6 & 35\end{array}$

3.3 The "cut" symbol $\quad 35$ 
$\begin{array}{lll}3.4 & \text { Exercise } 7 & 37\end{array}$

$\begin{array}{ll}3.5 & \text { Recursion in Prolog } \\ 3.6 & 37\end{array}$

$\begin{array}{lll}3.6 & \text { Exercise } 8 & 41\end{array}$

$\begin{array}{lll}3.7 & \text { Solutions to exercises } & 42\end{array}$

4 Lists and Complex Structures $\quad 45$

4.1 Lists in Prolog 45

4.2 The structure of lists $\quad 45$

4.3 Special list notation 46

4.4 Using lists and list notation $\quad 47$

$\begin{array}{lll}4.5 & \text { Exercise } 9 & 47\end{array}$

4.6 Incorporating more complex data

4.7 Manipulating the contents of lists 49

4.8 Exercise $10 \quad 51$

4.9 Solutions to exercises $\quad 52$

5 Interactive Programming using Prolog 53

5.1 Input of information to the program 53

5.2 Output of information to the user 54

$\begin{array}{lll}5.3 & \text { Exercise } 11 & 57\end{array}$

5.4 Some more system predicates $\quad 57$

$\begin{array}{lll}5.5 & \text { Exercise } 12 & 60\end{array}$

5.6 Getting Prolog to 'learn' 61

5.7 Generating multiple solutions inside

$\begin{array}{lll}5.8 & \text { Solutions to exercises } & 66\end{array}$

6 More Advanced Programming Tools $\quad 68$

6.1 Predicates for input and output 68

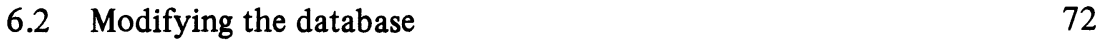

$\begin{array}{lll}6.3 & \text { Meta logical predicates } & 74\end{array}$

$\begin{array}{lll}6.4 & \text { Performing logical tests } & 76\end{array}$

$\begin{array}{lll}6.5 & \text { Operators } & 77\end{array}$

6.6 The Prolog high-level grammar syntax 80

7 The Debugging Facility 83

$\begin{array}{lll}7.1 & \text { The box model } & 83\end{array}$

$\begin{array}{lll}7.2 & \text { The debugging predicates } & 85\end{array}$

8 Case Studies $\quad 90$ 
Appendix 1: Prolog-1 (Version 2)

Appendix 2: Quintus Prolog (Version 1.2)

Appendix 3: A List of ASCII Characters and their Codes

Index 


\section{Preface}

\section{Prolog: an introduction to the language}

Since 1980, world-wide interest in the fields of Artificial Intelligence, Knowledge Processing and Expert Systems has increased. The spread of ideas associated with these subjects has been furthered by the announcement of the Japanese Fifth Generation Computing initiative, the response to that in the United States, the production in the U.K. of the Alvey report on Information Technology and European responses such as the ESPRIT program. The situation now is that most of those people who are seriously involved in computing whether as academics, professional practitioners or students - have some acquaintance with the concepts associated with Expert or Knowledge Based Systems.

In order to use the ideas, it has been necessary to find new ways of communicating our requirements to computer systems. Two languages in particular have emerged as the vehicles for developing and implementing Expert Systems - Prolog and LISP.

Both languages have attracted a dedicated user group because they offer a wider range of expression to the programmer than do other established languages. In brief, both languages allow, in their different ways, for the symbolic representation of some parts of human knowledge and reasoning.

Although they have some common characteristics, Prolog and LISP have different histories and, at the time of writing, there is a notable contrast in the way in which the languages have been implemented. LISP is the older language by more than a decade and the original development is credited to John McCarthy. LISP has been available as a usable language since the early sixties. Being essentially a simple and 'open' language, the strength of LISP is that its structure has allowed the development of beautifully engineered programming environments, examples of these being ZETALISP from MIT and INTERLISP-D from Xerox PARC. Running on dedicated machines with micro-coding capability (for example, Symbolics, Xerox 1108, LM1 lambda) these environments undoubtedly represent the most sophisticated programming tools available to us.

Prolog has a somewhat different history, having originated in Europe on the basis of work done by Alain Colmerauer and team at the University of Marseilles. Since the mid seventies much of the definitive development work on Prolog has 
been carried out in the U.K.

Up until a couple of years ago, LISP was regarded as the American Artificial Intelligence language and Prolog that of Europe. That situation is now changing and Prolog is gaining acceptance in the U.S.A. at the same time that powerful LISP environments are becoming extensively used in Europe.

Although there are as yet no specialised Prolog implementations that match the sophistication of the best LISP environments, it is only a matter of time before they are produced. Japan has selected Prolog as the base language for the Fifth Generation Programme and have stated that a primary objective is the development of a dedicated Prolog machine. A team at Berkeley University is currently working on the development of a similar system and there is work in that direction being carried out at Imperial College, London.

There are now a number of implementations of Prolog; some are excellent, others weak to the point of being little more than refined toys. The number of different 'dialects' means that there may be cases where examples used in this book will need to be restated to suit a different Prolog environment. The examples and test programs were constructed on the following systems, with minor changes in syntax.

The DEC-10 system running University of Edinburgh Prolog (Warren, Pereira, Byrd).

The SUN-2 system running Quintus Prolog (Artificial Intelligence Ltd). The IBM PC system running Prolog-1 (Expert Systems Ltd).

\section{About the book}

Our intention has been to produce a reference book which will allow students of the Prolog language to reach a good standard of proficiency in a fairly short period of time. As with all programming languages, there is a point at which the programmer must take over control of the learning process and build upon a basis of understanding in order to obtain the results he or she wants from the language. This is particularly true of Prolog because there are few constraints upon the power of expression that the language offers. It is possible to teach someone the syntax of the language but it is not entirely possible to teach people to use it productively - that comes with experience and motivation.

Although there is a considerable amount of theory and academic knowledge which is appropriate to the advanced study of Prolog, we have made a conscious decision to exclude most of it from this book. Much of it is treated in Programming in Prolog (Clocksin and Mellish; Springer-Verlag), and the reader is recommended to pass on to that text after assimilating this one.

Throughout the book, we have concentrated on obtaining practical results from the use of Prolog - thus the examples used tend to illustrate how a particular 
process can be implemented in Prolog and the reader is then (we hope) able to adapt the technique to his or her own requirements. By the time you have finished reading the book we very much hope that you will share our opinion that Prolog is a fascinating and delightful language to use, concealing great depth and power behind its apparent simplicity. 


\section{Acknowledgements}

The authors take great pleasure in expressing their thanks and appreciation to the following groups and individuals, without whom the book could not have been written:

Friends and colleagues at the Faculty of Engineering, Polytechnic of the South Bank. In particular John Hempstead, Chris Clare, Jack Dwyer, and Denbigh Gabbitas.

David Butler and the staff of Artificial Intelligence Ltd for encouragement, help and computing facilities.

Alex Goodall and the staff of Expert Systems International Ltd for their friendly co-operation.

The British Technology Group for their co-operation.

Lawrence Byrd and David Warren of the Quintus Corporation for their expertise and incisive comment. 